\title{
A Meta-Analysis of Observational Evidence for the Use of Endovascular Thrombectomy in Proximal Occlusive Stroke Beyond 6 Hours in Patients with Limited Core Infarct
}

\author{
James Wareham, BSc, MBChB, FRCR', Kevin Phan, BSc, MSc, MPhil', \\ Shelley Renowden, BSc, MBChB, MRCP, FRCR', Alex M Mortimer, BSc, MBChB, PhD, MRCS, FRCR'
}

Purpose: The safety and efficacy of endovascular thrombectomy (EVT) for patients with proximal occlusive stroke presenting beyond 6 hours and selected on the basis of favorable neuroimaging remains unclear.

Materials and Methods: A systematic search was performed from four electronic databases from their inception to Jan 2017. A meta-analysis of outcomes from studies with patients treated beyond 6 hours was compared to those treated within the established 6 hour therapeutic window in randomized trials, selected using conventional imaging methods with $\mathrm{CT} / \mathrm{CT}$ angiography.

Results: A total of 8 articles met inclusion criteria for the study population (a prospective single-center study, 5 retrospective single-center studies and 2 retrospective multicenter studies). These were compared to the results of three prospective trials of patients treated within 6 hours selected using $\mathrm{CT} / \mathrm{CT}$ angiography. For patients treated $>6$ hours and $<6$ hours respectively, the weighted mean age was 64.7 vs. 67.0 years; the presenting NIHSS was 15.7 vs. 17.1 and the time from symptom onset to puncture was 4.0 hours vs. 15.1 hours. Weighted pooled estimates of successful recanalization (TIMI $2 / 3$ or $\mathrm{TICl} 2 \mathrm{~b} / 3$ ) and favorable outcome ( $\mathrm{mRS} \leq 2$ ) were similar between both groups, $70.1 \%$ vs. $70.6 \%, \mathrm{P}=0.75$ and $38.9 \%$ vs. $38.4 \%, \mathrm{P}=0.88$ respectively. Pooled mortality measured at 3 months was $22.8 \%$ for those treated $>6$ hours and $12.5 \%$ for $<6$ hours, $P<0.0001$. Symptomatic intracranial hemorrhage was not significantly different $(10.0 \%$ vs. $7.7 \%, \mathrm{P}=0.33)$.

Conclusion: When compared to established methods of patient selection, EVT employed beyond 6 hours in those selected with imaging to exclude large core infarcts achieves similar rates of recanalization, and functional outcome but there is a significant increase in mortality despite no increase in symptomatic intracranial hemorrhage.

Key Words : Stroke; Thrombectomy; Endovascular; Perfusion; Infarct

'Department of Neuroradiology, North Bristol NHS Trust, Southmead Hospital, Bristol, BS10 5NB, United Kingdom

${ }^{2}$ NeuroSpine Surgery Research Group (NSURG), Level 7, Prince of Wales Private Hospital, Barker Street, Sydney, NSW, 2109, Australia Received July 28, 2017; Revised August 4, 2017; Accepted August 5, 2017.

Correspondence to: Dr. Alex M Mortimer, Department of Neuroradiology, North Bristol NHS Trust, Southmead Hospital, Bristol, BS10 5NB, United Kingdom.

Tel. +441179505050 E-mail: alex_mortimer@hotmail.com

This is an Open Access article distributed under the terms of the Creative Commons Attribution Non-Commercial License (http://creativecommons.org/licenses/by-nc/3.0) which permits unrestricted non-commercial use, distribution, and reproduction in any medium, provided the original work is properly cited. 


\section{James Wareham, et al.}

It is well established that early recanalization is associated with improved outcomes: in the recent Hermes analysis [1], rates of functional independence after endovascular thrombectomy (EVT) were 64\% with reperfusion at 3 hours vs. $46 \%$ with reperfusion at 8 hours. In this analysis, thrombectomy up to 7.3 hours after symptom onset was associated with improved outcomes. Inclusion of patients with $\mathrm{CT}$ and $\mathrm{CT}$ angiography (CTA) within 6 hours formed the basis for three of the recent trials [2-4] and this has led to construction of national and international guidelines incorporating these criteria [5-7].

Despite campaigns to heighten public awareness, a significant proportion of patients present to or are referred to comprehensive stroke centers offering interventional treatment beyond the six hour therapeutic window [8], with only $11-12 \%$ of UK stroke admissions in 2014 being eligible for IV thrombolysis [9]. It has been demonstrated that the size of the core infarct at presentation is highly variable and is independent of time from stroke onset [10]. The weight of evidence suggests that core infarct growth is heavily dependent on the collateral flow to the ischemic penumbra $[11,12]$. Factors that govern collateral failure are not well understood but it has been shown that in patients with good collaterals, only a minority will go on to have a favorable outcome without recanalization [13], suggesting that collaterals are finite and will only persist long enough minimize core growth until spontaneous thrombus autolysis in a small group of patients. It is, however, conceivable that a group of patients with small core infarct and persisting good collateral status may present or may be referred beyond the established therapeutic time window of six hours and may benefit from thrombectomy.

It has been demonstrated that in patients assessed using MR perfusion and treated within 12 hours, those patients with a mismatch between core and penumbra will benefit from reperfusion whereas those that show a matched defect will not [14]. Furthermore, these patients obtained superior outcomes when compared to another population of patients with a target mismatch treated with best medical therapy within the same time frame [15]. Recently, the results of the DAWN trial have been presented [16], suggesting a clear benefit for patients undergoing thrombectomy between 6 and 24 hours compared to best medical therapy when selected using well defined CT or MR perfusion criteria stipulating small core infarcts with clinico-radiological mismatch. We aimed to assess whether observational evidence obtained in real world practice employing imaging to exclude large core infarcts supported use of EVT after the established six hour therapeutic time window through comparison of results of recent positive trials that selected patients within this time window using conventional imaging with $\mathrm{CT}$ and CTA.

\section{MATERIALS AND METHODS}

\section{Literature Search Strategy}

Two reviewers systematically searched Ovid Medline, PubMed, Cochrane Central Register of Controlled trials and the Cochrane Database of Systematic Reviews from date of inception to January 2017. To maximize the sensitivity of the search strategy, specific terms were used as either Mesh Categories or key words, including: 'acute stroke', 'endovascular', 'mechanical thrombectomy', 'stent retriever', 'time-to-treatment'. Reference lists and citing articles were also reviewed to increase the identification of relevant studies.

\section{Selection Criteria}

Predefined criteria were selected prior to study review. Those that reported outcomes for acute anterior circulation stroke treated with mechanical thrombectomy in patients selected with MRI or CT techniques beyond 6 hours after symptom onset were included. All publications were published in the English language. Case reports, conference presentations, E-posters, reviews and abstracts were excluded.

The control population was taken from the results of recent randomized trials in which the patients were treated within six hours and selected using CT and CT angiography. This included patients treated in PISTE [2], MR CLEAN [3], and THERAPY [4]. Advanced imaging including collateral scoring on CTA, multiphase CTA, CT perfusion or MR imaging were included within SWIFT PRIME [17], THRACE [18], REVASCAT [19], ESCAPE [20], and EXTEND IA [21] trials and therefore, the results of these trials were not included within the control population.

Baseline demographics including presenting National Institute of Health Stroke Scale (NIHSS) score were extracted along with complicating time to reperfusion, symptomatic hemorrhage, degree of recanalization (Thrombolysis in Myocardial Infarction, TIMI 2 or 3 and Thrombolysis in Cerebral Infarction, TICI $2 b / 3$ were deemed as successful degrees of recanalization respectively), favorable outcomes (modified Rankin Scale, $\mathrm{mRS} \leq 2$ at 90 days), and 90 day mortality. 


\section{Endovascular Therapy for Acute Stroke Beyond 6 Hours}

\section{Data Extraction}

Two investigators (JW and AMM) independently reviewed each selected article and tabulated. This was subsequently checked prior to analysis by a third independent reviewer (KP) and papers were included by consensus. Data was extracted from the tables and figures available from each study. For continuous variables, standard deviations (SD) were collected as much as possible. When SD was not reported, it was estimated using range/4 or interquartile range (IQR)/1.35 [22, 23]. Each article was appraised according to the Dutch Cochrane Centre checklist proposed by the Meta-analysis of Observational Studies in Epidemiology (MOOSE) group. The key points included within these criteria include: (i) clear definition of the study population; (ii) clear definition of outcomes and outcome assessment; (iii) independent assessment of outcome parameters; (iv) sufficient duration of follow-up; (v) no selective loss during follow-up; and (vi) important confounders and prognostic factors identified.

\section{Statistical Analysis}

Following data extraction, comparative statistical analysis was made with the outcomes of three recently published studies assessing outcomes in acute anterior circulation stroke treated with thrombectomy $<6$ hours. A meta-analysis of proportions was conducted for the available main perioperative and postoperative variables. Firstly, to establish variance of raw proportions, a logit transformation was applied. To incorporate heterogeneity (anticipated among the included studies), transformed proportions were combined using DerSimonian-Laird random effects models. Finally the pooled estimates were back-transformed. Heterogeneity was evaluated using Cochran $\mathrm{Q}$ and $\mathrm{I}^{2}$ test. Weighted means were calculated by determining the total number of events divided by total sample size. Subgroup analysis was conducted according to timing of thrombectomy treatment $<6$ hours versus $>6$ hours. All

Table 1. Baseline Characteristics and Peri-Operative Outcomes for Those Treated $>6$ Hours Selected Using Advanced Imaging and for Those Treated $<6$ Hours Selected Using CT/CTA

\begin{tabular}{|c|c|c|c|c|c|c|c|c|c|c|c|}
\hline \multirow[t]{2}{*}{ Study } & \multicolumn{8}{|c|}{$\begin{array}{l}\text { Patients treated }>6 \text { hrs selected } \\
\text { using advanced imaging }\end{array}$} & \multicolumn{3}{|c|}{$\begin{array}{l}\text { Patients treated }<6 \text { hrs } \\
\text { selected using CT/CTA }\end{array}$} \\
\hline & $\begin{array}{l}\text { Abou- } \\
\text { Chebal }^{24}\end{array}$ & $\begin{array}{l}\text { Jovin } \\
\text { et } \mathrm{al}^{25}\end{array}$ & $\begin{array}{l}\text { Jung } \\
\text { et } \mathrm{al}^{26}\end{array}$ & $\begin{array}{l}\text { Gratz } \\
\text { et } \mathrm{al}^{27}\end{array}$ & $\begin{array}{l}\text { Natarajan } \\
\text { et } \mathrm{al}^{28}\end{array}$ & $\begin{array}{l}\text { Turk } \\
\text { et } \mathrm{al}^{29}\end{array}$ & $\begin{array}{c}\text { Abilleira } A \\
\text { et } \mathrm{al}^{30}\end{array}$ & $\begin{array}{l}\text { Aghaebrahim } \\
\text { et } \mathrm{al}^{31}\end{array}$ & PISTE $^{2}$ & $\begin{array}{c}\text { MR } \\
\text { CLEAN }^{3}\end{array}$ & $\begin{array}{l}\text { THER } \\
\text {-APY }\end{array}$ \\
\hline Patients & 21 & 237 & 128 & 22 & 30 & 70 & 52 & 128 & 33 & 233 & 55 \\
\hline $\begin{array}{l}\text { Age, years } \\
(\mathrm{M}=\text { mean/SD. } \\
\mathrm{m}=\text { median/IQR) }\end{array}$ & $\begin{array}{c}\text { M } 59.4 \\
(17.2)\end{array}$ & $\begin{array}{c}\text { M } 63.8 \\
(16)\end{array}$ & $\begin{array}{l}\text { M } 61.1 \\
(15)\end{array}$ & $\begin{array}{r}M 67.1 \\
(14.5)\end{array}$ & $\begin{array}{c}\mathrm{m} 72 \\
(24-91)\end{array}$ & M 64.9 & $\begin{array}{c}\text { M } 66.3 \\
(12.4)\end{array}$ & M 64 & $\begin{array}{c}M 67 \\
(17)\end{array}$ & $\begin{array}{c}\mathrm{m} 65.8 \\
(54.5-76.0)\end{array}$ & $\begin{array}{l}\text { M } 67 \\
(11)\end{array}$ \\
\hline Females N/\% & $8(38 \%)$ & $121(51)$ & $59(46.1)$ & $10(45.5)$ & $13(43)$ & $31(45 \%)$ & $21(40.4)$ & $43(41)$ & 20 (61\%) & 98 (42\%) & $38(21)$ \\
\hline $\begin{array}{l}\text { Onset To Puncture } \\
\text { hrs (M=mean/SD. } \\
\text { m=median/IQR) }\end{array}$ & $\begin{array}{c}M 18.6 \\
(16.0)\end{array}$ & $\begin{array}{c}M 15.0 \\
(11.2)\end{array}$ & $\begin{array}{c}\text { m 6.8 } \\
(6-24) \\
\text { M15 } \\
(13.3)\end{array}$ & $\begin{array}{c}\text { m } 10.35 \\
(8.2-23.7) \\
\text { M15.9 } \\
(11.5)\end{array}$ & $\begin{array}{c}\mathrm{m} 10.0 \\
(8-27.5) \\
\mathrm{M} 17.75 \\
(14.4)\end{array}$ & M18.3 & $\begin{array}{l}\text { M8.38 } \\
(3.25)\end{array}$ & $\begin{array}{c}\text { M } 18.2 \\
(33.6)\end{array}$ & $\mathrm{m} 3.5$ & $\begin{array}{l}\mathrm{m} 4.33 \\
(3.5-5.2)\end{array}$ & $\begin{array}{c}\mathrm{m} 3.8 \\
(3.06-4.4)\end{array}$ \\
\hline $\begin{array}{l}\text { Presenting NIHSS } \\
(\mathrm{M}=\text { mean/SD. } \\
\mathrm{m}=\text { median/IQR) }\end{array}$ & $\begin{array}{c}M 17.8 \\
(5.5)\end{array}$ & $\begin{array}{c}\text { M } 15.0 \\
(5.5)\end{array}$ & $\begin{array}{c}\text { M } 16.1 \\
(9.1)\end{array}$ & $\begin{array}{c}\text { m } 16.5 \\
(8-22) \\
\text { M15 } \\
(10.3)\end{array}$ & $\begin{array}{l}\mathrm{m} 12 \\
(5-22) \\
\mathrm{M} 13.5 \\
(12.6)\end{array}$ & M 15.1 & $\begin{array}{c}M 17.3 \\
(4.8)\end{array}$ & $\begin{array}{c}\text { M } 14.5 \\
(5.4)\end{array}$ & $\begin{array}{c}\mathrm{m} 18 \\
(6-24)\end{array}$ & $\begin{array}{c}\text { m 17 } \\
(14-21)\end{array}$ & $\begin{array}{c}\mathrm{m} 17 \\
(13-22)\end{array}$ \\
\hline $\begin{array}{l}\text { TICl 2b/3/TIMI 2/3 } \\
\text { N/\% }\end{array}$ & $\begin{array}{c}18 \\
(85.7)\end{array}$ & $\begin{array}{c}175 \\
(73.84)\end{array}$ & $\begin{array}{c}81 \\
(64.8)\end{array}$ & $\begin{array}{c}15 \\
(68.2)\end{array}$ & $\begin{array}{l}20 / 30 \\
(66.7)\end{array}$ & $\begin{array}{c}58 \\
(82.60)\end{array}$ & $\begin{array}{c}28 \\
(53.8)\end{array}$ & $\begin{array}{c}90 \\
(70)\end{array}$ & $\begin{array}{c}26 / 30 \\
(87)\end{array}$ & $\begin{array}{c}115 / 196 \\
(58.7)\end{array}$ & $\begin{array}{c}30 / 43 \\
(70)\end{array}$ \\
\hline $\begin{array}{l}\text { ICH Symptomatic } \\
\mathrm{N} / \%\end{array}$ & $\begin{array}{c}2 \\
(9.5)\end{array}$ & $\begin{array}{c}21 \\
(8.86)\end{array}$ & $\begin{array}{c}23 \\
(3.7)\end{array}$ & $\begin{array}{c}2 \\
(9.0)\end{array}$ & $\begin{array}{l}3 / 30 \\
(10)\end{array}$ & $\begin{array}{l}4 / 70 \\
(5.6)\end{array}$ & $\begin{array}{l}3 / 52 \\
(5.8)\end{array}$ & NA & 0 & $\begin{array}{c}18 \\
(7.7)\end{array}$ & $\begin{array}{l}4 / 43 \\
(9.3)\end{array}$ \\
\hline $\begin{array}{l}m R S \leq 2 \text { at } \\
3 \text { months } N / \%\end{array}$ & $\begin{array}{c}9 \\
(42.9)\end{array}$ & $\begin{array}{c}93 / 198 \\
(47.0)\end{array}$ & $\begin{array}{c}43 / 122 \\
(35.2)\end{array}$ & $\begin{array}{c}8 \\
(36.4)\end{array}$ & $\begin{array}{c}6 \\
(20)\end{array}$ & $\begin{array}{c}32 \\
(45.5)\end{array}$ & $\begin{array}{c}12 \\
(23.1)\end{array}$ & $\begin{array}{c}64 \\
(50)\end{array}$ & $\begin{array}{c}17 \\
(51.5)\end{array}$ & $\begin{array}{c}76 \\
(32.6)\end{array}$ & $\begin{array}{c}19 / 50 \\
(38)\end{array}$ \\
\hline 90 Day Mortality N/\% & $\begin{array}{l}\% \quad 5 \\
(23.8)\end{array}$ & $\begin{array}{c}51 \\
(21.5)\end{array}$ & $\begin{array}{c}32 / 122 \\
(26.2)\end{array}$ & $\begin{array}{c}4 \\
(18.2)\end{array}$ & $\begin{array}{c}9 \\
(33)\end{array}$ & $\begin{array}{c}15 \\
(21.2)\end{array}$ & $\begin{array}{c}11 \\
(21.2)\end{array}$ & $\begin{array}{l}28 \\
(22)\end{array}$ & $\begin{array}{c}7 \\
(21.2)\end{array}$ & $\begin{array}{c}21 / 233 \\
(9)\end{array}$ & $\begin{array}{l}6 / 50 \\
(12)\end{array}$ \\
\hline
\end{tabular}




\section{James Wareham, et al.}

analyses were performed using the metafor package for $R$ version 3.01. $P$ values $<0.05$ were considered statistically significant.

\section{RESULTS}

A total of 386 individual studies were identified from the four electronic databases. Following single reviewer evaluation of abstracts, 24 were identified as being eligible for assessment. The full text of these articles was assessed and 8 remaining articles fulfilled inclusion criteria. One study was a prospective single center study, 5 were retrospective single centre studies and 2 were retrospective multicenter studies (Table 1).

\section{Baseline Characteristics}

Baseline characteristics of the eight studies that met criteria for inclusion in this analysis [24-31] are summarized in Table 1. The total number of patients included was 688 . Four studies included patients presenting beyond 8 hours from symptom onset, 3 beyond 6 hours and 1 beyond 7 hours. The mean presenting NIHSS score was 15.7 and the mean time from symptom onset to puncture was 15.1 hours. Patient selection was made using a combination of either CT or MRI techniques in six studies, the two remaining studies utilized $\mathrm{CT}$ perfusion only. Recanalization was measured using the TIMI scoring system in 5 of the studies and the TICI system was employed in three studies. The control population contained data from three recent randomized trials [24], including 321 patients selected and treated within 6 hours on the basis of CT and CT angiography.

\section{Age and Sex}

No difference in presenting age was found between

Table 2. Imaging Criteria Applied in Each Study

\begin{tabular}{|c|c|}
\hline Study & Selection criteria \\
\hline Abou-Chebal ${ }^{24}$ & $\begin{array}{l}\text { CT perfusion mismatch defined by the presence of a low CBF region that measured } \geq 20 \% \text { of the low CBV } \\
\text { region. Exclusion if core infarct based on CBV map > one third of the MCA territory. }\end{array}$ \\
\hline Jovin et $\mathrm{a}^{25}$ & $\begin{array}{l}\text { Visual inspection of MRI or CTP scans demonstrating mismatch between core (DWI or CTP-CBV lesion) and } \\
\text { inadequately perfused brain (CBF, MTT, or TTP MRI or CTP maps). Exclusion if core infarct greater than one } \\
\text { third of the MCA territory. }\end{array}$ \\
\hline Jung et $\mathrm{a}^{26}$ & $\begin{array}{l}\text { NCCT assessed for core infarct and MR perfusion and diffusion weighted MR imaging mismatch assessed by } \\
\text { visual inspection. EVT not performed if no relevant diffusion-perfusion mismatch on MRI, if the spin-echo T2- } \\
\text { weighted images revealed clearly visible hyperintense T2 signal, or if the CT showed extensive hypodensity. }\end{array}$ \\
\hline Gratz et $\mathrm{al}^{27}$ & $\begin{array}{l}\text { Perfusion criteria not defined. The majority of patients underwent MRI (median ASPECTS } 6.5) .77 \% \text { showed } \\
\text { moderate-good leptomeningeal collateral flow on DSA. Patients undergoing CT only had a median ASPECTS } \\
\text { of } 8.5 \text {. No exclusion criteria but } 5(22 \%) \text { had extensive ischaemic changes defined as ASPECTS }<5 \text {. }\end{array}$ \\
\hline Natarajan et $a^{28}$ & $\begin{array}{l}\text { Patients with "significant salvageable brain tissue" were selected on the basis of preserved CBV maps. } \\
\text { Patients considered for treatment if established core infarct was less than one-third of the MCA territory or } \\
\text { ASPECTS } \geq 7 \text {. }\end{array}$ \\
\hline Turk et al29 & $\begin{array}{l}\text { MTT/CBF defined penumbra and CBV defined core mismatch. Patients in whom one-third or more of the } \\
\text { MCA territory was core infarct or with } \leq 50 \% \text { penumbra were not considered candidates for endovascular } \\
\text { treatment. }\end{array}$ \\
\hline Abilleira et $a^{30}$ & $\begin{array}{l}\text { Perfusion imaging not defined. CT ASPECTS }<7 \text { and DWI ASPECTS }<6 \text { or patients with well-developed } \\
\text { parenchymal hyperintensity seen on FLAIR or pronounced hypodensity on CT affecting the ischemic region } \\
\text { excluded. }\end{array}$ \\
\hline Aghaebrahim et $\mathrm{a}^{31}$ & $\begin{array}{l}\text { Patients included if CT showed an ASPECTS score }>6 \text { or less than one-third hypodensity within the MCA } \\
\text { territory. CT perfusion CBV/MTT mismatch or CBV/NIHSS mismatch considered. Patients with a core volume } \\
\text { less than a third of the vascular territory involved in the presence of an anterior circulation large vessel } \\
\text { occlusion and corresponding clinical deficit (NIHSS }>6-8 \text { ) or severe perfusion deficit (MTT }>145 \% \text { contralat- } \\
\text { eral side) involving two-thirds or more of the vascular territory involved were considered for EVT. }\end{array}$ \\
\hline
\end{tabular}

ASPECTS: Alberta Stroke Program Early CT Score; CBF: Cerebral Blood Flow; CBV: Cerebral Blood Volume; CTP: CT Perfusion; DSA: Digital Subtraction Angiography; DWI: Diffusion Weighted Imaging; MCA: Middle Cerebral Artery; MTT: Mean Transit Time; NCCT: Noncontrast CT; NIHSS: National Institute of Health Stroke Scale; TTP: Time to Peak 
the two groups ( 67 vs. 64.7 years for $<6$ hours and $>6$ hours respectively, $\mathrm{P}=0.24$ ). The proportion of females was also similarly matched (43.8\% vs. $43.6 \%, \mathrm{P}=0.92)$.

\section{Imaging selection criteria}

Imaging used to select patients in each study is described in Table 2.

\section{Time to puncture and presenting NIHSS}

The pooled mean of time to puncture, defined as time from symptom onset to groin puncture was 4.0 vs. 15.1 hours, $\mathrm{P}=0.001)$. The presenting NIHSS score was greater for the $<6$ hour group (17.1 vs. $15.7, \mathrm{P}=0.02$ ).

\section{Procedural Parameters}

Weighted pooled estimates of successful recanalization (defined as TICI $2 \mathrm{~b} / 3$ or TIMI $2 / 3)$ were $(70.6 \%$ (95\% CI: $53.3-83.5)$ vs. $70.1 \%$ (95\% CI: $63.4-76.0)$, $\mathrm{P}=0.75)$ for patients treated $<6$ hours and $>6$ hours respectively (Fig. 1). Symptomatic intracranial hemorrhage was similar between the two populations: (7.7\% (95\% CI: $5.1-11.4)$ vs. 10.0 (95\% CI: 6.7-14.7, $\mathrm{P}=0.33)$; see Figure 2.

\section{Functional outcomes and mortality}

Favorable outcome (defined as $\mathrm{mRS} \leq 2$ ) was found to be similar (38.4\% (95\% CI: $28.9-48.9)$ vs. $38.9(95 \%$ CI; 31.9-46.4), $\mathrm{P}=0.88$ ); see Figure 3. Mortality was significantly higher for those selected using perfusion and treated beyond 6 hours $(12.5 \%$ (95\% CI: 7.3-20.4) vs. $22.8 \%$ (95\% CI: 19.8-26.1, p<0.0001); see Figure 4.

\section{DISCUSSION}

Analysis of the recent randomized control trials assessing outcomes for proximal large vessel occlusive ischemic stroke treated with EVT has demonstrated a clear benefit over intra-venous thrombolysis alone/best

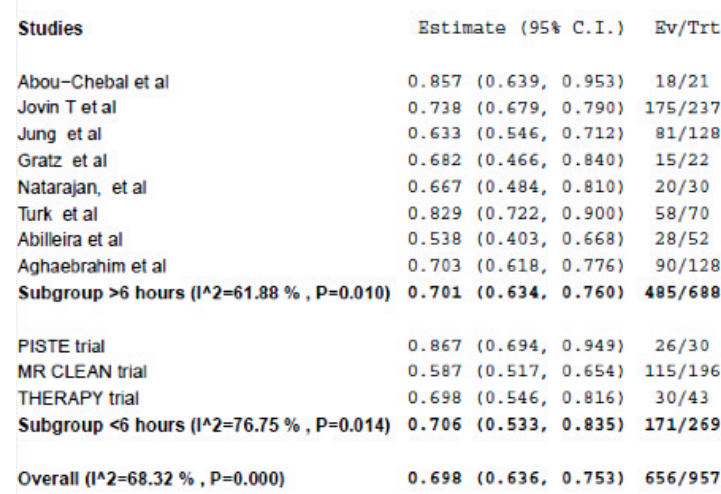

年

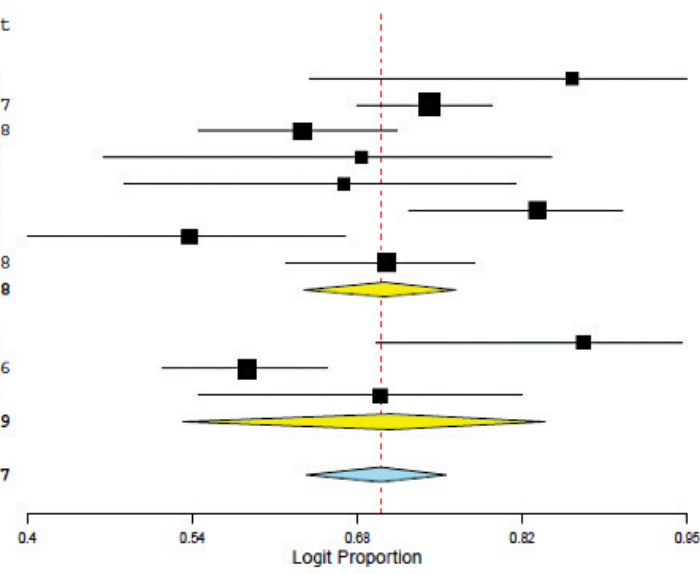

Fig. 1. Forest plot for recanalisation ( $\mathrm{TIMI} 2 / 3$ or $\mathrm{TICI} 2 \mathrm{~b} / 3$ ).

Studies
Abou-Chebal et al
Jovin T et al
Jung et al
Gratz et al
Natarajan, et al
Turk et al
Abilleira et al
Subgroup $>6$ hours $\left(I^{\wedge} 2-45.14 \%, P-0.090\right)$
PISTE trial
MR CLEAN trial
THERAPY trial
Subgroup $<6$ hours $\left(I^{\wedge} 2-0 \%, P-0.446\right)$
Overall $(\mid \wedge 2=40.08 \%, P=0.090)$
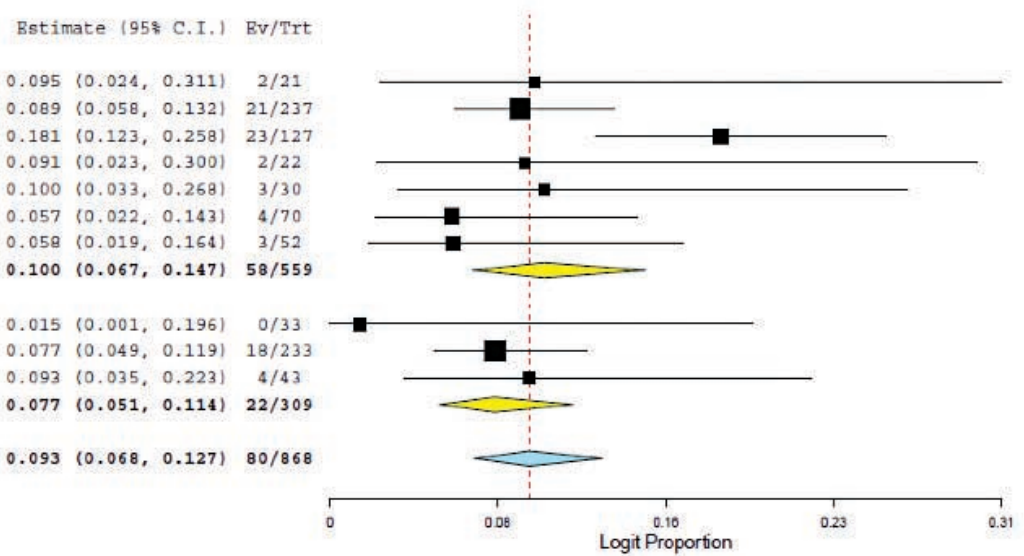

Fig. 2. Forest plot for symptomatic intracranial haemorrhage. 


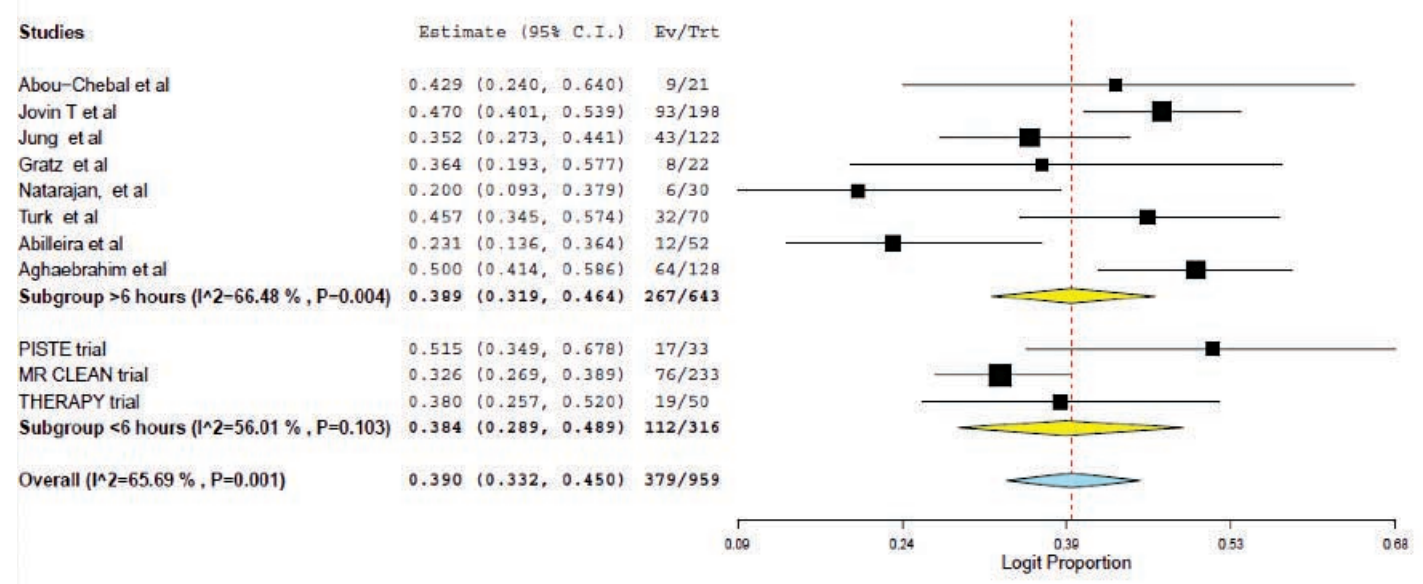

Fig. 3. Forest plot for favorable outcome (mRS $\leq 2)$.

Studies
Abou-Chebal et al
Jovin T et al
Jung et al
Gratz et al
Natarajan, et al
Turk et al
Abilleira et al
Aghaebrahim et al
Subgroup $>6$ hours $(\mid \wedge 2-0 \%, P-0.934)$
PISTE trial
MR CLEAN trial
THERAPY trial
Subgroup <6 hours (I^2-53.69\%, P-0.11
Overall (I^2-58.49\%, P-0.007)

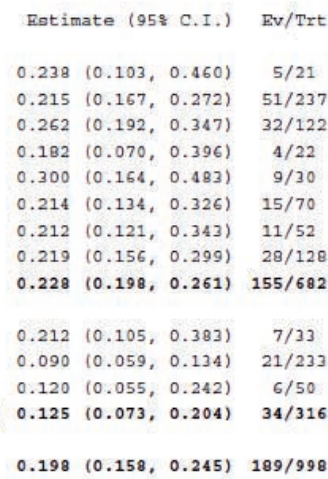

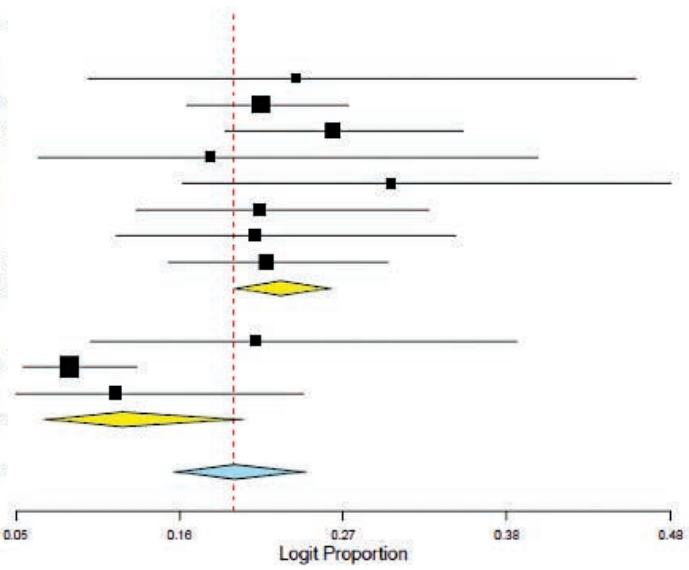

Fig. 4. Forest plot for 90 day mortality.

medical therapy within a 7.3 hour therapeutic window from symptom onset [1]. Three trials relied on use of CT and CTA for patient selection and treatment within 6 hours. The other trials used various advanced imaging techniques including multiphase CTA, collateral scoring, CT or MR perfusion or diffusion imaging. Nevertheless, it is well established that favorable outcome rate falls with time from symptom onset, but, is has been established that core infarct size is independent of time to presentation [4] and it is well documented that collateral flow is critical in stroke physiology [32]. A robust collateral network may be associated with smaller initial infarct volumes, reduced rates of infarct growth, improved outcomes, reduced rates of procedural related intra-cranial hemorrhage and increased rates of successful recanalization $[33,34]$ Good collaterals alone do not guarantee a favorable outcome [7] and recanalization is key to achieving this.
The DEFUSE 2 study demonstrated that those patients with a target mismatch treated with EVT showed benefit from reperfusion whereas those that show a matched defect did not [14]. More recently, it has been shown that these patients obtained superior outcomes when compared to another population of patients with a target mismatch treated with best medical therapy [15] It is possible, therefore, that even for those patients presenting beyond the established therapeutic time window, there is a subset with favorable collateral status and small core infarct (hence a target mismatch) that may also benefit from thrombectomy.

The results of the eagerly awaited DAWN trial [16] were presented recently, reporting a $35 \%$ absolute increase in the number of patients achieving independence with number needed to treat of 2.8 after undergoing thrombectomy selected using advanced imaging after 6 hours. Selection criteria for those under 80 years 
included an NIHSS $>10$ with core infarct volume of $<31 \mathrm{ml}$ or NIHSS score of $>20$ with core $<51 \mathrm{ml}$ and for those over 80 years, an NIHSS of $>10$ and core of $<21 \mathrm{ml}$. In this analysis, all patients other than five were selected on the basis of a core infarct $<$ one third of the MCA territory, or on the basis of the absence of T2 hyperintensity on MRI or low CT or MR ASPECTS (Alberta Stroke Program Early CT Score) score. Furthermore, all patients other than 74 from two of the studies included $[27,30]$ were defined as having a mismatch on perfusion imaging. Perfusion imaging was recommended in one of these studies that provided 52 patients [30] but a mismatch was not defined as a criterion for inclusion and we have no data on the proportion with a mismatch in this study. The imaging criteria in this analysis are therefore heterogenous and less selective than those used in the DAWN trial. However, they more likely reflect clinical practice.

We aimed to assess whether available observational evidence obtained in real world practice supported the approach of treating patients beyond 6 hours on the basis of favorable imaging with limited core infarct. We also aimed to assess whether comparable results to those achieved using conventional imaging selection (CT/CTA) for patients treated within 6 hours could be obtained. It is somewhat artificial to compare these groups but the latter group of patients selected using CT/CTA within 6 hours represent selection criteria included in many national/international guidelines and the data are taken from prospective trials selecting on this basis. The study population included in this metaanalysis comprised patient selection using either CT or MRI to identify a limited core infarct with the majority undergoing perfusion techniques to identify a mismatch beyond the standard 6 hour therapeutic window. With a mean time of presentation to puncture of 15.1 hours, the patients showed good functional outcome $(\mathrm{mRS} \leq 2)$ in $38.9 \%$. This was not significantly different to rates of independence encountered in the control population treated within 6 hours selected using conventional imaging ( $\mathrm{mRS} \leq 2$ in $38.4 \%$ ), $\mathrm{P}=0.88$. The delayed recanalisation group did show a significant increase in mortality compared to those treated within the conventional time window ( $12.5 \%$ vs. $22.8 \%, \mathrm{P}<0.0001)$. However, the rate of symptomatic intra-cranial hemorrhage did not differ significantly $(7.7 \% \mathrm{vs}$. $10.0 \%, \mathrm{P}=0.33$ ).

It is likely that selecting patients on the basis of CT and CTA will lead to treatment of a proportion of patients with a matched core and penumbra despite undergoing a procedure within 6 hours. The superior outcomes obtained in the EXTEND-IA trial [21] that selected on the basis of a target mismatch identified with CT perfusion within 6 hours does go some way to proving this. The favorable outcome rate $(\mathrm{mRS} \leq 2)$ in this trial was $66 \%$. Furthermore, Turk et al. [27] demonstrated that there was no significant difference in functional outcome for those selected on the basis of a target mismatch on CT perfusion treated before or after 7 hours, with the median treatment time in the latter group being 13 hours.

It is not clear from available results why there was increased mortality in the delayed treatment group. This modest increase in symptomatic intracranial hemorrhage, did not reach statistical significance, and on the face of it is unlikely to have contributed to the increase in mortality. The use of older endovascular technology in a significant proportion is a confounder and could have been a factor [35]. However, recanalization rates and hemorrhage were not dissimilar so this impact is uncertain. The 'no reflow phenomenon' would hopefully be avoided through the use of perfusion imaging and selection of patients with a mismatch. One possible explanation and a question raised by the results is whether reperfusion injury is more common in this group. Reperfusion injury is characterized by a complex interaction between activated inflammatory mediators and the endothelial layer of the capillary wall resulting in capillary plugging, breakdown of the blood brain barrier and infiltration of localized brain parenchyma with cytokines [36]. This inflammatory cascade leads to an increased tendency towards hemorrhagic transformation and increased cerebral edema respectively [36]. However, these studies excluded patients with a large core infarct so again, the impact of reperfusion injury is uncertain. What is necessary is to ascertain the mortality from the natural history for this population of late presenters with a limited core infarct.

Successful recanalization was achieved in $70.1 \%$ of the study population selected using perfusion imaging $>6$ hours, comparing well with the trial data (TICI $2 \mathrm{~b} / 3$ in $70.6 \%$ ) despite use of older technology in a significant proportion. Thrombus characteristics are a potential factor in determining recanalization rate. It is well established that the attenuation characteristics of acute thrombus reduce with time as red cell rich clots evolve to more fibrin rich variants [37]. Authors who have found lower rates of recanalization with more fibrin rich clots therefore suggest that thrombi become more difficult to remove with time [37]. Thrombus length, or 'clot burden' is inversely related to outcome 
and successful recanalization with an increasing clot burden score being associated with worse functional outcomes and larger final infarcts volume [37-39]. Clot burden is however independent of time and is instead related to collateral status [40]. Potential explanations for this relationship include improved access of the distal clot to thrombolytics from retrograde filling and reduced stasis preventing clot propagation [41]. We therefore suggest that although the constituents of clot change with time, these target lesions will not necessarily be of long length, a relationship that may balance difficulty of clot extraction in this patient cohort.

This analysis is limited through inclusion of a number of single centre retrospective studies but this reflects the best estimate that we have currently of real-world practice with less stringent selection criteria that may be encountered in the trial scenario. The studies varied in inclusion criteria: most looked specifically at anterior circulation stroke however two included a small percentage of posterior circulation strokes and wake-up strokes respectively [24-27]. Jung et al. [27] included patients with a baseline NIHSS score $\geq 4$, or isolated hemianopia whereas Turk et al. [29] included patients with an NIHSS $>8$ with any symptomatology. The imaging modalities and protocols varied between studies. For example, Abou-Chebal [24] included patients only selected with CT perfusion whereas Jovin et al. [25] utilized NCCT and MR perfusion with different studies employing different exclusion criteria based on imaging. Although there is inherent variability in the information provided between imaging modalities and also between different manufacturers and systems within each modality, for practical use to decision-make in this setting good agreement has been found [42]. Finally, recanalization was measured using different grading systems in the study cohort with both TICI and TIMI scoring utilized. A study comparing the different scales has however shown comparable outcomes for patients with TICI $2 b / 3$ and TIMI $2 / 3$ recanalization [43] and therefore the impact of this on results is likely minimal. These limitations should be considered when interpreting the results of this review.

\section{CONCLUSION}

Recent studies have shown a clear benefit of EVT over IV-TPA alone in acute large vessel occlusive ischemic stroke within 6 hours of symptom onset. Our pragmatic meta-analysis of observational studies suggests that the rates of recanalization and good functional outcome are not significantly different to this in patients treated beyond 6 hours when selected on the basis of desirable imaging characteristics demonstrating limited core infarction (the majority defined as core of less than one third the MCA territory). We also demonstrated an increase in mortality but no difference in the rate of symptomatic intracranial hemorrhage. The reasons for this increase in mortality remain unclear based on available data. Although the results of prospective studies investigating this clinical scenario are eagerly awaited, these results suggest that patients who present in a delayed manner with a limited core infarct may benefit from recanalization with thrombectomy.

\section{References}

1. Saver JL, Goyal M, van der Lugt A, Menon BK, Majoie CB, Dippel DW, et al. Time to Treatment With Endovascular Thrombectomy and Outcomes From Ischemic Stroke: A Metaanalysis. JAMA 2016;316:1279-1288

2. Muir KW, Ford GA, Messow CM, Ford I, Murray A, Clifton A, et al. Endovascular therapy for acute ischaemic stroke: the Pragmatic Ischaemic Stroke Thrombectomy Evaluation (PISTE) randomised, controlled trial. J Neurol Neurosurg Psychiatry 2017;88:38-44

3. Berkhemer OA, Fransen PS, Beumer D, van den Berg LA, Lingsma HF, Yoo AJ, et al. A Randomized trial of Intraarterial treatment for acute Ischemic stroke. N Engl J Med 2015;372:1120

4. Mocco J, Zaidat OO, von Kummer R, Yoo AJ, Gupta R, Lopes D, et al. Aspiration Thrombectomy After Intravenous Alteplase Versus Intravenous Alteplase Alone. Stroke 2016;47:2331-2338

5. White PM, Bhalla A, Dinsmore J, James M, McConachie N, Roffe C, et al. Standards for providing safe acute ischaemic stroke thrombectomy services. Clin Radiol 2017;72:175.e1-175.e9

6. ESO Karolinska Consensus Stroke Update Consensus statement (2015) http://2014strokeupdate.org/consensus-statement-mechanical-thrombectomy-acuteischemic-stroke

7. Powers WJ, Derdeyn CP, Biller J, Coffey CS, Hoh BL, Jauch EC, et al. 2015 American Heart Association/American Stroke Association Focused Update of the 2013 Guidelines for the Early Management of Patients With Acute Ischemic Stroke Regarding Endovascular Treatment: A Guideline for Healthcare Professionals From the American Heart Association/American Stroke Association. Stroke 2015;46:3020-3035

8. Addo J, Ayis S, Leon J, Rudd AG, McKevitt C, Wolfe CD. Delay in presentation after an acute stroke in a Multiethnic population in south London: The south London stroke register. Original Research 2012;1:1685

9. HQIP. SSNAP acute organisational audit report. (2016) http://www.hqip.org.uk/resources/ssnap-acute-organisational-auditreport

10. Hakimelahi R, Vachha B, Copen W, Papini GD, He J, Higazi $\mathrm{MM}$, et al. Time and diffusion lesion size in major anterior circulation ischemic strokes. Stroke 2014;45:2936-2941

11. Campbell BC, Christensen S, Tress BM, Churilov L, Desmond 


\section{Endovascular Therapy for Acute Stroke Beyond 6 Hours}

PM, Parsons MW, et al. Failure of collateral blood flow is associated with infarct growth in ischemic stroke. J Cereb Blood Flow Metab 2013;33:1168-1172

12. Bang OY, Goyal M, Liebeskind DS. Collateral circulation in ischemic stroke: Assessment tools and therapeutic strategies. Stroke 2015;46:3302-3309

13. Miteff F, Levi C, Bateman G, Spratt N, McElduff P, Parsons MW. The independent predictive utility of computed tomography angiographic collateral status in acute ischaemic stroke. Brain 2009;132:2231-2238

14. Lansberg MG, Straka M, Kemp S, Mlynash M, Wechsler LR, Jovin TG, et al. MRI profile and response to endovascular reperfusion after stroke (DEFUSE 2): a prospective cohort study. Lancet Neurol 2012;11:860-867

15. Wouters A, Lemmens R, Christensen S, Wilms G, Dupont P, Mlynash $\mathrm{M}$, et al. Magnetic resonance imaging-based endovascular versus medical stroke treatment for symptom onset up to $12 \mathrm{~h}$. Int J Stroke 2016;11:127-133

16. Jovin T. Diffusion-weighted imaging or computerized tomography perfusion assessment with clinical mismatch in the triage of wake up and late presenting strokes undergoing neurointervention with Trevo (DAWN). 3rd European Stroke Organisation Conference (ESOC) 2017 May 16 - 18, 2017 Prague, Czech Republic

17. Saver JL, Goyal M, Bonafe A, Diener HC, Levy EI, Pereira VM, et al. Stent-Retriever Thrombectomy after intravenous t-pA vs. tpA alone in stroke. $N$ Engl J Med 2015;372:2285-2295

18. Bracard S, Ducrocq X, Mas JL, Soudant M, Oppenheim C, Moulin T, et al. Mechanical thrombectomy after intravenous alteplase versus alteplase alone after stroke (THRACE): a randomised controlled trial. Lancet Neurol 2016;15:1138-1147

19. Jovin TG, Chamorro A, Cobo E, de Miquel MA, Molina CA, Rovira A, et al. Thrombectomy within 8 hours after symptom onset in Ischemic stroke. N Engl J Med 2015;372:2296-2306

20. Goyal M, Demchuk AM, Menon BK, Eesa M, Rempel JL, Thornton J, et al. Randomized assessment of rapid endovascular treatment of ischemic stroke. N Engl J Med 2015;372:1019-1030

21. Campbell BC, Mitchell PJ, Kleinig TJ, Dewey HM, Churilov L, Yassi N, et al. Endovascular therapy for ischemic stroke with perfusion-imaging selection. N Engl J Med 2015;372:1009-1018

22. Hozo SP, Djulbegovic B, Hozo I. Estimating the mean and variance from the median, range, and the size of a sample. $B M C$ Med Res Methodol 2005; 5:13

23. Cochrane Handbook http://handbook.cochrane.org/chapter_7/ 7_7_3_5_mediansand_interquartile_ranges.htm

24. Abou-Chebal A. Endovascular treatment of acute ischemic stroke may be safely performed with no time window limit in appropriately selected patients. Stroke 2010;41:1996-2000

25. Jovin T, Liebeskind D, Gupta R, Rymer M, Rai A, Zaidat OO, et al. Imaging-based endovascular therapy for acute ischemic stroke due to proximal intracranial anterior circulation occlusion treated beyond 8 hours from time last seen well: retrospective multicenter analysis of 237 consecutive patients. Stroke 2011;42:2206-2211

26. Jung S, Gralla J, Fischer U, Mono ML, Weck A, Lüdi R, et al. Safety of endovascular treatment beyond the 6-h time window in 205 patients. Eur J Neurol 2013;20:865-871

27. Gratz P, Jung S, Schroth G, Gralla J, Mordasini P, Hsieh K, et al. Outcome of standard and high-risk patients with acute anterior circulation stroke after stent retriever thrombectomy. Stroke 2014;45:152-158

28. Natarajan SK, Snyder KV, Siddiqui AH, Ionita CC, Hopkins LN, Levy EI. Safety and effectiveness of Endovascular therapy after 8 hours of acute Ischemic stroke onset and wake-up strokes. Stroke 2009;40:3269-3274

29. Turk A, Nyberg E, Chaudry M, Turner RD, Magarik JA, Nicholas JS, et al. Utilization of CT perfusion patient selection for mechanical thrombectomy irrespective of time: a comparison of functional outcomes and complications. J Neurointerv Surg 2013;5:518-522

30. Abilleira S, Cardona P, Ribó M, Millán M, Obach V, Roquer J, et al. Outcomes of a contemporary cohort of 536 consecutive patients with acute ischemic stroke treated with endovascular therapy. Stroke 2014;45:1046-1052

31. Aghaebrahim A, Leiva-Salinas C, Jadhav A, Jankowitz B, Zaidi S, Jumaa $\mathrm{M}$, et al. Outcomes after endovascular treatment for anterior circulation stroke presenting as wake-up strokes are not different than those with witnessed onset beyond 8 hours. $J$ Neurointerv Surg 2015;7:875-880

32. Telischak NA, Wintermark M. Imaging predictors of procedural and clinical outcome in endovascular acute stroke therapy. Neurovasc Imaging 2015;1:4

33. Sheth SA, Sanossian N, Hao Q, Starkman S, Ali LK, Kim D, et al. Collateral flow as causative of good outcomes in endovascular stroke therapy. J Neurointerv Surg 2016;8:2-7

34. Liebeskind D, Tomsick T, Foster L, Yeatts SD, Carrozzella J, Demchuk AM, et al. Collaterals at angiography and outcomes in the Interventional management of stroke (IMS) III trial. Stroke 2014;45:759-764

35. Saver JL, Jahan R, Levy EI, Jovin TG, Baxter B, Nogueira RG, et al. Solitaire flow restoration device versus the Merci Retriever in patients with acute ischaemic stroke (SWIFT): a randomised, parallel-group, non-inferiority trial. Lancet 2012; 380:1241-1249

36. Pan J, Konstas A-A, Bateman B, Ortolano GA, Pile-Spellman J. Reperfusion injury following cerebral ischemia: Pathophysiology, MR imaging, and potential therapies. Neuroradiology 2006;49:93102

37. Liebeskind DS, Sanossian N, Yong WH, Starkman S, Tsang MP, Moya AL, et al. CT and MRI early vessel signs reflect clot composition in acute stroke. Stroke 2011;42:1237-1243

38. Riedel CH, Zimmermann P, Jensen-Kondering U, Stingele R, Deuschl G, Jansen O. The importance of size: successful recanalization by intravenous thrombolysis in acute anterior stroke depends on thrombus length. Stroke 2011;42:1775-1777

39. Shobha N, Bal S, Boyko M, Kroshus E, Menon BK, Bhatia R, et al. Measurement of length of Hyperdense MCA sign in acute Ischemic stroke predicts disappearance after IV tPA. $J$ Neuroimaging 2013;24:7-10

40. Puetz V, Dzialowski I, Hill MD, Subramaniam S, Sylaja PN, Krol A, et al. Intracranial Thrombus extent predicts clinical outcome, final infarct size and Hemorrhagic transformation in Ischemic stroke: The clot burden score. Int J Stroke 2008;3:230-236

41. Qazi EM, Sohn SI, Mishra S, Almekhlafi MA, Eesa M, d'Esterre $\mathrm{CD}$, et al. Thrombus Characteristics Are Related to Collaterals and Angioarchitecture in Acute Stroke. Can J Neurol Sci 2015;42: 381-388

42. Schramm P, Schellinger PD, Klotz E, Kallenberg K, Fiebach JB, Külkens S, et al. Comparison of perfusion computed tomography 


\section{James Wareham, et al.}

and computed tomography angiography source images with perfusion-weighted imaging and diffusion-weighted imaging in patients with acute stroke of less than 6 hours' duration. Stroke 2004;35:1652-1658
43. Marks MP, Lansberg MG, Mlynash M, Kemp S, McTaggart R, Zaharchuk G, et al. Correlation of AOL recanalization, TIMI reperfusion and TICI reperfusion with infarct growth and clinical outcome. J Neurointerv Surg 2014;6:724-728 